\section{The Compatibility of Digitalization and Human Relations in Enhancing Knowledge Creation: A Prerequisite for Organizational Agility}

\author{
Geoffrey Lugwisha \\ International School For Social And Business Studies, Slovenia \\ geoffrey@kvcctz.org
}

Management,

Economy for a New Normal: Digitalisation and Human Relations in Business and Education 20-21 May 2021 Online Conference

\begin{abstract}
Purpose: This study looks at the compatibility of digitalization and human relations in enhancing knowledge creation, which in turn, serves as a prerequisite for organizational agility. Also, the purpose of the study is to make initial testing of the model of relationships between the concepts under research, with emphasis on digitalization and human relations concepts as to how they are compatible in enhancing knowledge creation, hence organizational agility, and to prepare the framework for further research.
\end{abstract}

Study design/methodology/approach: This study used the qualitative methodology, with the use of content analysis, with the participants being determined by purposive sampling.

Findings: First, findings show that digitalization does have beneficial effects on both human relations and the organization, as far as knowledge creation and agility are concerned. Second, findings show that digitalization and healthy human relations are compatible and that their compatibility serves to enhance knowledge creation, which in turn serves as a catalyst to enhance organizational agility. Third, findings showed the concerns of privacy and confidentiality being jeopardized. Fourth, findings showed the need for improvement in the area of empowering workers to be more conversant with digitalization without undermining the concept of healthy human relations.

Originality/value: It is hereby declared that this submission is the own work of the author and to his best knowledge it contains no materials previously published or written by another person.

Keyword: Digitalization, Human Relations, Knowledge Creation, Organizational AgilityR

\section{Introduction}

In the current highly turbulent, competitive, unpredictable, changing, unprecedented world environment, organizations need to be agile to be successful. The situation is in a way forcing organizations, both small and big, to be more agile to survive and thrive. Organizational agility is seen as among the significant tools for gaining and maintaining efficient and competitive advantage (Almahamid, 2018, pp. 28-33; Nafei, 2016, pp. 296-309; Zitkiene and Deksnys, 2018, pp.115-129). On the other hand, the need to have agile organizations thrive and succeed in today's challenging and complex world makes it paramount to have organizations leveraging on knowledge management. The focus of this paper is on knowledge creation, a knowledge management process. It is argued in this paper that knowledge creation could serve to enhance organizational agility. However, digitalization and human relations are two compatible elements that could serve to enhance knowledge creation in an organization (Almahamid, 2018, pp. 28-33; Marhraoui and Manouar, 2017, pp. 21-36; Salavati and Reshadat, 2014, pp.10511065).

It is in this perspective that this study looks at the compatibility of digitalization and human relations in the enhancement of knowledge creation as a prerequisite for organizational agility, specifically in Tanzania. That is, the study identifies the positive relationship between digitalization and human relations in the enhancement of knowledge creation processes, which 
serves as a prerequisite for enhancing organizational agilities in organizations in the context of Tanzania.

There is an increasing global awareness of the important role of digital technologies in the achievement of performance and competitive advantage in organizations. However, the human aspect, in terms of human capital and relations remains to have a crucial role in the achievement of an organization's competitive edge and success. When digital technologies are in a way that healthy interactions among employees are maintained, they could enhance a culture of innovation, sharing and the creation of new knowledge (Fedorova, Koropets, and Gatti, 2019, pp.1-10). In the same context, knowledge management processes, such as knowledge creation, enhanced by technology, could be considered as among critical success factors in today's organizational agility, serving to improve and maintain it in an organization (Almahamid, 2018, pp. 28-33; Marhraoui and Manouar, 2017, pp. 21-36; Salavati and Reshadat, 2014, pp. 10511065; Yaghoubi and Dahmardeh, 2011, pp.272-277).

It is in this context that this study aims at looking at the compatibility of digitalization and human relations in enhancing knowledge creation, which in turn, serves as a prerequisite for organizational agility. Also, the study aims to make initial testing of the model of relationships between the concepts under research, with emphasis on digitalization and human relations concepts as to how they are compatible in enhancing knowledge creation, hence organizational agility, and to prepare the framework for further research.

\section{Literature Review}

In our literature review, we look at the connectedness of digitalization, human relations, knowledge creation, and organizational agility. It is argued that the development of digital infrastructure and the development of electronic services should go hand in hand with the development of human capital and human relations. It is to be ensured that the technological modernization of production, services provision, and business processes, in general, does not undermine the enhancement of human capital development and human relations. The phenomena of digital culture that encompasses aspects such as personal computer, internet, mobile communications, digital means of communications, etc., should be taken positively as opportunities for improving human knowledge, skills, and relations (Zaborovskaia, Nadezhina, and Avduevskaya, 2020, pp.1-24).

Technology has emerged to facilitate life in organizations. New technologies are changing the usual functionality of workers. Digital tools are introduced in business processes, including human resources management processes. Digitalization is a tool that speeds up the communication process by reducing cost and helping organizations be more productive and work more efficiently and be more effective. Digitalization in human resource management is seen as helpful to enterprises to modernize human resource functions and provides them with a competitive advantage. Digitalization is seen to be helpful in areas such as performance appraisals to be done online, in recruitment and selection, training, data analysis, mobile technologies, social networking, etc. Digitalization in human resource management helps enterprises to modernize human resource functions and provides them with a competitive advantage (Lumi, 2020, pp.39-46).

It is also argued that digitalization should be understood as a technological process that could serve to improve human resource management by making it more efficient and effective by facilitating its functions and processes. However, the primary basis of an organization is people, and digital tools are to be used by people and at the same time maintain healthy human relations (Lumi, 2020, pp.39-46). It is in this manner that digitalization and healthy human relations 
could move together to make organizations efficient, relevant, improve their organizational performance, and gain a competitive advantage (Halid, Yusoff, and Somu, 2020, p.96-99).

It is argued that the technological processes of digitalization have enhanced effective performance in productivity, innovation, speed, and adaptiveness. They have proven to be helpful in dynamics such as working with large amounts of data (big data), computer-aided training, use of artificial intelligence for personnel selection and evaluation, organizing employee feedback online, etc. Moreover, digitalization is seen to remove barriers between work and personal life as employees are available almost anytime and anywhere. On the other hand, it is noticed that it has transformed human resource to make them more effective and relevant in today's competitive business environment, as through it, all human resource work is managed using soft technologies, applications and the internet. The most significant thing that is noticeable is that digital technologies are seen to enhance a culture of innovation and sharing. The culture of innovation and sharing are key elements in the processes of knowledge sharing and creation (Fedorova, Koropets, and Gatti, 2019, pp.1-10; Halid, Yusoff, and Somu, 2019, pp. 96-99).

The benefits of the use of digital technologies in organizations are evident. Digitalization processes have helped create effective internal communications, automating processes of information exchange and reporting, reducing operating expenses, teleconferencing, speed, ease of documentation, less paperwork, ease in collecting comparative data, improved performance, etc. The integration of digital technology into business processes is said to be crucial for the survival and competitive advantage of contemporary organizations (Fedorova, Koropets, and Gatti, 2019, pp.1-10; Fenech, Baguant, and Ivanov, 2019, pp.1-10).

Indeed, digitalization has revolutionized the way organizations relate to their customers, how they relate among themselves, how they run their operations, how they organize themselves. Technology, and hence digital technologies, and human capital in organizations are seen more as working together in a synergistic effect that results in sustained competitive advantage. However, human capital is to be skilled and knowledgeable to meet the digitalization needs of the present and future (Fenech, Baguant, and Ivanov, 2019, pp.1-10).

However, it is argued that digital technologies must fit with the organizational culture, core values, and be supported by a proper combination of human resource management practices, especially being characterized by human relations (Fedorova, Koropets, and Gatti, 2019, pp.110). Digitalization and human relations could move together to make organizations efficient, relevant, improve their organizational performance, and gain a competitive advantage. Digitalization could enable people to be more informed and more engaged. Digital tools and media could enable organizations to connect and also could enable employees to communicate and interact with others (Halid, Yusoff, and Somu, 2020, p.96-99). Digital technologies should be in a way that healthy interactions among employees are maintained. It is through these interactions that human relations are built, which then build the environment for knowledge sharing and creation to place in an organisation (Fedorova, Koropets, and Gatti, 2019, pp.1-10).

Human relations could be defined as entailing the interactions that exist between people, both formally and informally, both in people's personal work lives and the communication of skills. Human relations are ways in which people relate to each other and how they work together in groups, especially at work, satisfying both individual needs and group objectives. Human relations could enhance the achievement of organizational objectives. It is argued that, for organizations to succeed, then they should ensure that relationships among the people in them must be developed, improved, monitored, and maintained (Lawrence, 2014, pp.53-62).

While there may be some fears to some as they perceive digital technologies as a threat for human employees work and job, yet when positively taken, digital technologies could facilitate 
interactions among employees, thus enhance human relations, and thus create an environment for knowledge sharing and creation (Fedorova, Koropets, and Gatti, 2019, pp.1-10).

The ongoing compatibility of digitalization and human relations could foster among things, strategic thinking, innovative mindset, sustaining creativity, new experiences, and knowledge. Indeed, the connectedness of the above-mentioned things is wrapped in a culture that fosters the creation of knowledge which could, in turn, enhance agility in an organization. Both corporate and public organizations could then experience organizational agility which is vital in thriving, succeeding, respond effectively to the people's needs, produce products and provide (manage) services in new approaches (Dahmardeh and Pourshahabi, 2011, pp. 95-111; Harraf et al, 2015, pp. 675-686; Parker and Bartlett, 2008, pp.1-35; Turqieh, Aoun, and Nasr, 2018, pp.1-14).

As it is further argued, the enhancement of knowledge creation through the compatibility of digitalization and human relations could be evident in dynamics such as the provision of better services, best practices, cutting edge thinking and developments in good management, leveraging innovation, new methods of service delivery, quick and right decision making, technologies to enhance service delivery mechanisms, and enhancing human capital (Dahmardeh and Pourshahabi, 2011, pp. 95-111; Parker and Bartlett, 2008, pp.1-35; Turqieh, Aoun, and Nasr, 2018, pp.1-14).

The increasing importance of knowledge in performance, productivity, profitability, managing services, and competitive advantage is undeniable. Furthermore, knowledge creation, characterized by digitalization and human relations that enrich sharing, is identified as an important driver of agility and could enhance organizational agility (Almahamid, 2018, pp. 2833; Marhraoui and Manouar, 2017, pp. 21-36; Salavati and Reshadat, 2014, pp. 1051-1065; Yaghoubi and Dahmardeh, 2011, pp.272-277).

Organizational agility, which could be defined as the organization's ability to recognize changes in the environment and appropriately respond swiftly and accordingly, effectively and efficiently through the utilization of internal resources such as the know-how, experience, knowledge of the organization, and its decision-makers for its thriving and success; is highly needed for organizations to survive and succeed in today's challenging environments (Zikiene and Deksnys, 2018, pp.115-129).

With organizational agility being achieved by being enhanced by new knowledge creation processes, organizations should be able to achieve their goals and objectives, survive, thrive and succeed (Almahamid, 2018, pp. 28-33; Marhraoui and Manouar, 2017, pp. 21-36; Salavati and Reshadat, 2014, pp. 1051-1065; Yaghoubi and Dahmardeh, 2011, pp.272-277). The issue then is how do organizations in Tanzania see the compatibility of digitalization and human relations in enhancing knowledge creation as a prerequisite for organizational agility. The model of relationships between the concepts under research is as presented in Figure 1 below.

Figure 1: The model of relationships between the concepts under research

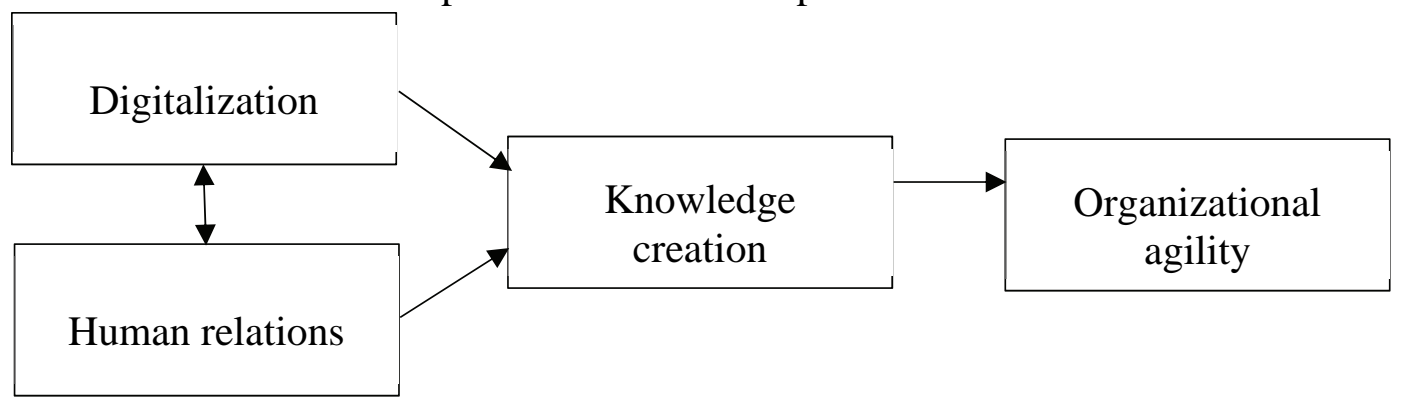

Source: Researcher, 2021. 
As pointed out earlier in the introduction, the aim of the study is also to make initial testing of the model of relationships between the concepts under research as presented in Figure 1 above, with emphasis on digitalization and human relations as to how they are compatible in enhancing knowledge creation, hence organizational agility, and to prepare the framework for further research.

\section{Methodology}

This study aimed to analyze the compatibility of digitalization and human relations in the enhancement of knowledge creation as a prerequisite for organizational agility, specifically in Tanzania; and also to make initial testing of the model of relationships between the concepts under research, with emphasis on digitalization and human relations concepts as to how they are compatible in enhancing knowledge creation, hence organizational agility, and to prepare the framework for further research. The qualitative methodology, with the use of content analysis, was the main research method used in this study. A content analysis of the accounts from the interviews of 21 participants was conducted. In performing the content analysis, the interviews were made into transcripts; thereafter categories were identified from which themes were identified as well, and eventually, the compilation was done. The participants were determined by purposive sampling and varied from public organizations, corporate organizations, and NGOs. Participants were taken who are conversant with their professions and in using digital technologies, and who hold key positions in their organizations. The selection was done by ensuring that participants are taken who could give insights appropriate for the undertaken study (Bengtsson, 2016, pp.8-14; Mohajan, 2018, pp. 23-51; Palmer and Bolderston, 2006, pp.16-19; Wong, 2014, pp. 130-140). Indeed, they gave a good and helpful response, corporation, and insights during the interviews.

\section{Findings And Discussion}

There is a significant association between digitalization, human relations, knowledge creation, and organizational agility. The study findings show the support of the fact that the compatibility of digitalization and healthy human relations serve to enhance knowledge creation in an organization, which in turn, enhances organizational agility. Four issues did resurface from the findings.

First, it can be said that digitalization does have beneficial effects on both human relations and the organization, as far as knowledge creation and agility are concerned. All interviewed participants were of the assertion that digitalization has made the operations and functions in their organizations more effective and efficient. It has eased the execution of tasks and activities, reduced costs, has increased speed and saves time, has made communication effective, and has made workflow more effective. A participant commented saying, "I do see digitalization as being quite beneficial in our institute. We no longer spend a lot of expenditure in convening face to face meetings as we use video or teleconference facilities. Also, in the past, it would cost us a lot in storing documents and in transferring them from one destination to another. But nowadays we simply use computers and our intranet system."

Another participant commented saying, "Ours is an international organization with the headquarters in the USA and a country office here in Dar es Salaam, Tanzania. With the headquarters in the USA, and being a global organization, yet all operations and functions run smoothly through our organization's intranet structure. We work at home due to the Covid-19 pandemic, and once a while we go to the office. However, even before this Covid-19 pandemic, we would collect data and consolidate it through digital technology; interviews and meetings 
are done online, and basically, all systems and activities such as procurement, human resources, and all others are digitalized. This cuts down costs, is speedy and saves time, is efficient and effective."

This is well supported by literature in which it is asserted that digitalization serves to enhance effective performance in productivity, innovation, speed, and adaptiveness. It is helpful in dynamics such as working with large amounts of data (big data), computer-aided training, use of artificial intelligence for personnel selection and evaluation, organizing employee feedback online, human resource, etc. (Fedorova, Koropets, and Gatti, 2019, pp.1-10; Halid, Yusoff, and Somu, 2019, pp. 96-99). Moreover, the benefits of the use of digital technologies in organizations are evident, in dynamics such as creating effective internal communications, automating processes of information exchange and reporting, reducing operating expenses, teleconferencing, speed, ease of documentation, less paperwork, ease in collecting comparative data, improved performance, etc. (Fedorova, Koropets, and Gatti, 2019, pp.1-10; Fenech, Baguant, and Ivanov, 2019, pp.1-10).

It is an undeniable fact that digitalization is well accepted in organizations in Tanzania. Generally, it can be said that digitalization has revolutionized production, service delivery, administrative functions and operations, businesses, and workflows in organizations in Tanzania. It shows employers and employees are comfortably satisfied with what digitalization has brought to their organizations.

Second is the issue of digitalization versus human resources, and their connectedness to knowledge creation and hence organizational agility. It can be said that digitalization and healthy human relations are compatible. Their compatibility serves to enhance knowledge creation, which in turn serves as a catalyst to enhance organizational agility. All participants were of the perception that although digitalization does reduce the face-to-face engagement and interaction among people in an organization and between organizations and organizations, yet interacting, engaging, and collaborating remains to be there through digital technologies.

It can be said that interacting, engaging, and collaborating through digital technologies such as the intranet, internet, WhatsApp, webinar, zoom, and all such others, do facilitate the sharing of information, ideas, skills, experiences, knowledge, and that mentorship dynamics can take place. This does foster the building of a culture of healthy relationships in an organization. Such dynamics facilitate the environment for acquiring knowledge, learning, growth, and for new ideas to emerge up. It indeed facilitates the environment for knowledge sharing and creation. One participant commented on this saying, "A person gets in the organization not having the know-how on something, but over time he or she gets to have it. For instance, I started working in my organization in the procurement section. But today I am in the forwarding and clearing section, effectively serving our customers." Another participant commented saying, "Digitalization could still help build relationships even with a person have never met face to face." It is said that through healthy relationships people can work together effectively and create new knowledge together.

This is an agreement with literature that asserts, the most significant thing is that digitalization is seen to enhance a culture of innovation and sharing. The culture of innovation and sharing fostered by healthy relations are key elements in the processes of knowledge sharing and creation. Moreover, digitalization must fit with the organizational culture, core values, and be supported by healthy human relations. Digitalization could enable people to be more informed, more engaged, communicate, and interact with others. Digitalization should serve to maintain healthy interactions among employees and therefore build the environment for knowledge sharing and creation to place in an organization (Fedorova, Koropets, and Gatti, 2019, pp.1-10; Halid, Yusoff, and Somu, 2020, p.96-99). 
While it is true that social gatherings are scaled down to a minimum, according to most of the participants, yet each one of them admitted that teamwork, collaborations, groups dynamics are facilitated, in which interactions, engaging with one another, collaboration, innovation, and sharing can effectively take place. Moreover, dynamics of information storage, knowledge storage and application are well facilitated by digitalization in the organization. Indeed, knowledge creation could be fostered rather than being hampered. The fostering of knowledge creation, in turn, fosters agility. The organization is capacitated to be able to respond swiftly to changes, innovate, and make decisions that will keep the organization surviving and on the move towards the realization of its goals even in challenging environments.

Third, almost all participants raised the concerns of privacy and confidentiality being jeopardized. This could be jeopardized by hackers to the intranet system of the organization, but also the access of the various individuals to a person's office computer which could cause leakage of information. As one participant would say, "A person needs not to trust a hundred per cent that your organization's information won't be lost or stolen or leaked." However, it is said that such won't remove completely the trust to share and collaborate, which could foster the processes of creating knowledge that is needful for the organization to succeed and remain agile.

It is argued that, in fact, some fears in digitalization may exist as some perceive digital technologies as a threat to human relations, work, job, and issues as mentioned above. However, when positively taken, digital technologies could facilitate interactions, engaging, and collaborations that create an environment for knowledge sharing and creation (Fedorova, Koropets, and Gatti, 2019, pp.1-10). The issue is to have digital technologies in use with harmony to maintaining healthy human relations that facilitate the environment of learning and sharing, which is conducive to knowledge creation. Agility would always need an ongoing culture of learning and creating knowledge.

Fourth, was the issue of the need for improvement in the area of empowering workers to be more conversant with digitalization without undermining the concept of healthy human relations. People need to be trained to make use of digital technologies in enhancing the dynamics of interactions, engaging, and collaboration, which will foster the enrichment of human relations. As one participant would point out saying, "I think that organizations should not only facilitate their workers with the technological tools but also equip them through training and encouraging them to use digital technologies; with emphasis on nurturing relationships without forgetting the importance of human relations in the organization." Another commented saying, "The technological infrastructures need to be improved more as far as digitalization in our organization is concerned. But I also feel that people in our organization need to train to use them in a meaningful way that the interactions will harness healthy relationship through which we will experience the emergence of new knowledge in our organizations. I strongly believe with sustainability in new knowledge, our organization will maintain agility."

Almost all participants were of the consent that digitalization is unavoidable in the contemporary world and that at the same time human relations cannot be underestimated if knowledge creation processes for the success and agility of organizations is to be achieved. It is in that manner that people in organizations need to be empowered to use the digital technologies in place to be more interactive, and have the freedom to share information, ideas, opinions, experiences, and knowledge, that which will eventually facilitate the creation of known knowledge in the organization. In that manner, the organization will be propelled to success and agility. In a similar context it is argued in the literature that human capital in organizations need to be skilled and knowledgeable to be able to meet the digitalization needs 
of the present and the future, including the aspect of healthy human relations thereof (Fenech, Baguant, and Ivanov, 2019, pp.1-10); and enhance new knowledge creation, a critical success factor for organizational agility (Almahamid, 2018, pp.28-33; Yaghoubi and Dahmardeh, 2011, pp.272-277)

Indeed, these results showed that organizations need to be aware of the compatibility of digitalization and human relations. These two elements should not be seen in contradiction of one another, but rather be seen as a key factor in enhancing knowledge creation. The enhanced knowledge creation is needful for organizational agility as its critical success factor for the organization to survive, thrive, and succeed in today's challenging environments.

\section{Conclusion}

This study shows that for organizations in Tanzania to survive, thrive, and succeed in today's challenging environments, the compatibility of digitalization and human relations in the enhancement of knowledge creation should not be undermined. While digitalization is unavoidable in today's contemporary world set-up, emphasis should be on how it moves towards compatibility with enriching human relations, and therefore, foster for dynamics such as sharing and collaboration, needful for knowledge creation and hence success and agility. It is therefore acknowledged that the compatibility of digitalization and human relations serves to enhance knowledge creation, which in turn serves as a catalyst and a critical success factor that enhances organizational agility.

Limitations in this study could have mainly been due to a lack of prior research studies on the covered topic and specifically in the country, bearing in mind that the focus was in Tanzania. Also, there were some limitations on the sharing of the information that seemed to be sensitive or confidential to be shared by the participants as pertaining to their particular organizations. However, efforts were done to ensure that all needful information was collected for the successful study endeavour.

It is suggested that further research be done on the subject matter to contribute more knowledge in the covered areas. It is hoped that this study will stir up more researches to be done and that it will be helpful to organizations in the country in their pursuit of survival, thriving, and success.

\section{References}

Almahamid, S. (2018). Knowledge Management Processes and Workforce Agility: A Theoretical Perspective. International Journal of Management and Applied Science, 4(7): 28-33.

Bengtsson, M. (2016). How to Plan and Perform a Qualitative Study Using Content Analysis. Nursing Plus Open, 2:8-14.

Dahmardeh, N, and Pourshahabi, V. (2011). Agility Evaluation in Public Sector Using Fuzzy Logic. Iranian Journal of Fuzzy Systems, 8(3): 95-111.

Fedorova, A., Koropets, O., and Gatti, M. (2019). Digitalization of Human Resource Management Practices and its Impact on Employees' Wellbeing. Conference Paper, pp.1-10. www.researchgate.net/publication/333075755, 27/3/2021.

Fenech, R., Baguant, P., and Ivanov, D. (2019). The Changing Role of Human Resource Management in an Era of Digital Transformation. International Journal of Entrepreneurship, 22(2):1-10.

Halid, H., Yusoff, Y.M., and Somu, H. (2020). The Relationship Between Digital Human Resource Management and Organizational Performance. Advances in Economics, Business and Management Research, (141):9699.

Harraf, A., Wanasika, I., Tate, K., Talbott, K. (2015). Organizational Agility. The Journal of Applied Business Research, 31(2): 675-686.

Lawrence, H. (2014). Integrating Human Relations Skills Into The Curriculum of Industrial Technology Related Programs. International Journal on Integrating Technology in Education (IJITE), 3(1):53-62. 
Lumi, A. (2020). The Impact of Digitalisation on Human Resources. Prizren Social Science Journal, 4(3): 3946.

Marhraoui, M.A. and Manouar, A.E. (2017). Towards a New Framework Linking Knowledge Management Systems and Organizational Agility: An Empirical Study. International Journal of Computer Science \& Information Technology, 9(1): 21-36.

Mohajan, H. (2018). Qualitative Research Methodology in Social Sciences and Related Subjects. Journal of Economic Development, Environment and People, 7(1):23-51.

Nafei, W. (2016). Organizational Agility: The Key to Organizational Success. International Journal of Business and Management, 11(5): 296-309.

Palmer, C., and Bolderston, A. (2006). A Brief Introduction to Qualitative Research. The Canadian Journal of Medical Radiation Technology, 16-19.

Parker, S. and Bartlett, J. (2008). Towards Agile Government. London, UK: Demos. Melbourne, Australia: The State Services Authority.

Salavati, A. and Reshadat, S. (2014). The Relationship Between Knowledge Management and Organizational Agility in the Branches of Bank Tejarat in the City of Sanandaj. Indian Journal of Fundamental and Applied Life Sciences, 4(1): 1051-1065.

Turqieh, G., Aoun, H., and Nasr, E. (2018). Agile in the Public Sector. Deloitte, A Middle East Point of View, Spring, pp. 1-14.

Wong, P.W. (2014). A Snap Shot on Qualitative Research Method. Educational Research and Reviews. Academic Journals, 9(5): 130-140.

Yaghoubi, N. and Dahmardeh, M.R. (2011). Knowledge Management; Critical Success Factor in Organizational Agility. American Journal of Social and Management Sciences, 2(3): 272-277.

Zaborovskaia, O., Nadezhina, O., and Avduevskaya, E. (2020). The Impact of Digitalisation on the Formation of Human Capital at the Regional Level. Journal of Open Innovation, 6(184):1-24.

Zitkiene, R. and Deksynys, M. (2018). Organizational Agility Conceptual Mode. Montenegrin Journal of Economics, 14(2): 115-129. 